\title{
VIOLÊNCIA CONTRA MULHERES NO BRASIL E NO URUGUAI: AS EXPERIÊNCIAS DA LEI MARIA DA PENHA E DA LEI DE VIOLÊNCIA DOMÉSTICA ${ }^{1}$ VIOLENCE AGAINST WOMEN IN BRAZIL AND URU- GUAY: THE EXPERIENCES OF THE MARIA DA PENHA LAW AND DOMESTIC VIOLENCE LAW \\ Mari Cleise Sandalowski* Gabriela Felten da Maia** \\ Paola Stuker** Maruá Pereira Lock ${ }^{* * * *}$
}

RESUMO: : O presente trabalho resulta de um estudo sociológico sobre as situações violência conjugal contra mulheres. $\mathrm{O}$ enfoque teóricometodológico orienta-se pela perspectiva da sociologia jurídica. O objetivo da pesquisa foi realizar um estudo sobre as mudanças implementadas pelas leis de violência contra mulheres existentes no Brasil e no Uruguai, em suas aplicações sucedidas nas relações conjugais. Foram selecionadas três regiões do Estado do Rio Grande do Sul (norte, centro e fronteira) e uma cidade uruguaia, fronteira com o Brasil, onde se analisaram dados referentes aos anos de 2005 a 2009, a partir de coleta em delegacias do Rio Grande do Sul e dos informativos sobre violência no Uruguai. Observou-se que a violência conjugal está presente no cotidiano das mulheres dessas regiões, independente dos seus contextos socioeconômicos e culturais. Apesar dos avanços, as leis de proteção às mulheres são limitadas, especialmente no que tange à proteção e prevenção dessa forma de violência.

Palavras-chave: Violência contra mulher; Lei Maria da Penha; Lei de Violência Doméstica; Cartografia da Violência; Sociologia Jurídica.

\footnotetext{
1 Pesquisa financiada pelo CNPq.

* Doutora em Sociologia pela Universidade Federal do Rio Grande do Sul (UFRGS); Professora do Departamento de Ciências Sociais e do Programa de Pós-Graduação em Ciências Sociais da Universidade Federal de Santa Maria (UFSM); Santa Maria, RS, Brasil; e-mail: mari_ppgs@yahoo.com.br

** Mestre em Ciências Sociais pela Universidade Federal de Santa Maria (UFSM); Professora do Departamento de Ciências Humanas da Universidade de Santa Cruz do Sul (UNISC), Santa Cruz do Sul, RS, Brasil; e-mail: gabryelamaia@gmail.com

*** Mestre e doutoranda em Sociologia pela Universidade Federal do Rio Grande do Sul (UFRGS), Porto Alegre, RS, Brasil; e-mail: stukerp@gmail.com

**** Licenciada em Sociologia pela Universidade Federal de Santa Maria (UFSM), Santa Maria, RS, Brasil; e-mail: marualock@gmail.com
} 
ABSTRACT: This work results from a sociological study of the marital situations violence against women. The theoretical and methodological approach is guided by the perspective of legal sociology. The objective was to conduct a study on the changes implemented by the laws of existing violence against women in Brazil and Uruguay in its successful applications in marital relations. We selected three regions of Rio Grande do Sul (north, center and border) and a Uruguayan town on the border with Brazil, which examined data for the years 2005-2009, from collection in police stations of Rio Grande do South and information on violence in Uruguay. It was observed that domestic violence is present in the daily lives of women in these regions, regardless of their socio-economic and cultural contexts. Despite the advances, laws to protect women are limited, especially with regard to the protection and prevention of this form of violence.

Key-words: Violence against women, Maria da Penha Law, Domestic Violence Law, Mapping Violence, Legal Sociology.

\section{INTRODUÇÃO}

A violência contra a mulher é um problema social que ultrapassa fronteiras nacionais. Este conflito vem emergindo como uma temática a ser debatida em diversos países desde os anos 70. Na última década, com a implementação de legislações que preveem a punição dos agressores, a violência contra a mulher torna-se o centro dos debates sobre a operacionalidade da Justiça. No caso do Brasil e do Uruguai, isto se dá com a promulgação da Lei 11.340/2006 (Lei Maria da Penha) e da Lei 17.514/2002 (Lei de Violência Doméstica), respectivamente.

Se antes da promulgação destas leis estes tipos de violência eram muito pouco investigados pelos diversos órgãos do sistema judiciário destes dois países, já que eram percebidos pelos seus agentes, principalmente pela polícia, como delitos brandos em relação à criminalidade urbana que comporta furtos, crimes à propriedade, dentre outros, a partir de meados dos anos dois mil - contexto de surgimento destas novas leis - delineou-se um novo espaço para a publicização destes conflitos. 
Contudo, nestes últimos anos, embora tenha havido a ampliação no espaço judicial para a denúncia destes delitos, já que eles passaram a serem analisados com base em leis específicas, os estudos sobre esta temática, assim como o movimento de mulheres, tem colocado em pauta a continuidade da banalização e trivialização da violência contra a mulher pelo sistema judiciário e por outras instâncias da sociedade. Seu argumento está relacionado à "aparente" impunidade dos agressores e na dificuldade de conciliar e resolver estes tipos de conflito. Esta lógica desqualificaria o problema da violência contra a mulher, tornando-a um elemento a mais na discriminação contra as mulheres.

É neste sentido que se torna necessária uma investigação que contemple avaliar o impacto das mudanças implementadas pela Lei 11.340/2006 e a Lei 17.514/2002 em sua aplicação aos casos de violência contra a mulher, especialmente aquelas sucedidas nas relações conjugais, no norte, centro e fronteira do Rio Grande do Sul e no Uruguai, mais especificamente nas cidades de Erechim, Santa Maria, Sant'Ana do Livramento, no Brasil, e Rivera, no Uruguai, entre os anos de 2005 e 2009, congregando uma indagação paralela acerca deste impacto na Delegacia de Polícia de Proteção à Mulher e Comisarías de la Mujer y la Familia.

Deste modo, acredita-se que a importância desta pesquisa contemple três questões relevantes para a Sociologia. Primeiro, esse trabalho justifica-se pela escassez de estudos sobre a aplicação da Lei Maria da Penha no cotidiano social e os impactos deflagrados pelas suas mudanças no cotidiano do sistema judicial em relação aos casos de violência conjugal contra a mulher, nas cidades de Erechim, Santa Maria e Sant'Ana do Livramento.

Segundo, a importância de se realizar um estudo comparativo sobre a aplicação da referida lei em cidades do interior e da fronteira do Rio Grande do Sul, bem como com a experiência uruguaia que desde 2002 aprovou uma lei específica para os casos de violência doméstica, mas que desde 1995 já qualificava a violência contra a mulher como um delito dentro do código penal do país.

Terceiro, a ênfase em uma abordagem que ultrapassa o modelo fundado na dicotomização de vítimas, de um lado, e acusados 
de práticas de agressão, de outro. Assumindo uma perspectiva que entende que estas mulheres, embora vítimas de violência, também estão investidas de parcelas de poder, pois, ao recorrerem ao sistema judicial para efetuar a denúncia, utilizam-o para reverter a situação conflituosa vivenciada no cotidiano, tornado pública, então, a agressão vivida. Nisto, elas deixam de ser passivas para tornarem-se sujeitos ativos na relação que possuem com seus companheiros.

Deste modo, a escolha teórico-metodológica que orienta este trabalho e que privilegia o enfoque da sociologia jurídica em detrimento dos estudos de gênero justifica-se pelos poucos estudos da Sociologia Jurídica sobre a aplicação das leis de proteção à mulher no cotidiano social, bem como sobre os seus impactos no sistema judicial em relação aos casos de violência conjugal contra a mulher, visto que as pesquisas sobre a temática até o momento têm enfatizado basicamente os estudos de gênero. Estas, em geral, dão destaque à abordagem qualitativa na investigação, enfatizando as representações sociais de vítimas, acusados e operadores de direito a partir da categoria gênero (Corrêa, 1983; Gregori, 1993; Saffioti\& Almeida, 1995; Saffioti, 2000, Debert\& Oliveira, 2004).

Estudos que contemplem a estrutura e o funcionamento do campo jurídico, para além de uma leitura de gênero, em relação à violência conjugal contra a mulher, não são representativos no âmbito das Ciências Sociais, em especial na Sociologia Jurídica.

Tradicionalmente as abordagens com foco na violência contra a mulher, violência doméstica e violência de gênero enfatizam as questões de ordem subjetiva (relacionadas às experiências das mulheres e suas percepções sobre o cotidiano social) e as dinâmicas decorrentes das relações estabelecidas através dos movimentos sociais (com destaque aos elementos políticos e organizacionais) (Olesen, 2006), constituindo-se em um modelo fundado na dicotomização entre vítimas e acusados de práticas de agressão (com ênfase na compreensão das estruturas locais de dominação, procurando, por consequência, produzir resistências a estas). Essa leitura dicotômica da violência contra a mulher tem sido problematizada por algumas autoras do campo dos estudos feminista de gênero. A 
ênfase deste trabalho insere-se nessa perspectiva não dual ao buscar compreender os elementos formais e informais que influenciam na forma como a legislação é aplicada, visto que o campo jurídico é um espaço perpassado por aspectos simbólicos, sociais, culturais, que (re)produzem a moralidade de uma determinada sociedade.

Deste modo, o presente artigo está divido em quatro partes. Na primeira seção apresenta-se uma breve análise do modo pelo qual se dá o acesso e a administração da justiça em relação à violência conjugal contra a mulher na contemporaneidade. Na segunda seção pontua-se a diferença entre o processo de judiciarização e judicialização que acompanham a racionalidade do direito moderno, destacando-se os alcances e limites do sistema judiciário e das legislações na prevenção à violência conjugal. A terceira seção apresenta dados relativos ao número de ocorrências sobre violência conjugal registradas nas delegacias de polícia de cada região analisada, assim como informações relativas ao tipo de violência conjugal mais recorrente. Por fim, na quarta seção é estabelecido um estudo comparativo entre a Lei Maria da Penha/Brasil e a Lei de Violência Doméstica/ Uruguai com o objetivo de examinar os mecanismos de proteção à mulher existentes no Brasil e no Uruguai.

\section{O ACESSO E A ADMINISTRAÇÃO DA JUSTIÇA EM RE- LAÇÃO À VIOLÊNCIA CONJUGAL CONTRA A MULHER}

Uma análise das situações de violência conjugal contra a mulher requer não apenas um debate sobre as condições sociais responsáveis pelas estruturas e aspectos simbólicos que orientam as percepções dos indivíduos sobre os significados de masculinidade e feminilidade na sociedade ocidental contemporânea. É necessário também investigar como estas percepções sociais são produzidas e reproduzidas na esfera formal do sistema de justiça, assim como os encaminhamentos racionais-formais a elas destinados.

Ao debruçar-se sobre o fenômeno jurídico, Boaventura de Sousa Santos (2010) explica que é somente a partir da década de sessenta, do século passado, que os estudos que envolvem a temática dos tribu- 
nais deixam de ter uma abordagem predominantemente normativista e substantivista do direito e passam a destacar as perspectivas institucionais e organizacionais para investigar o campo jurídico.

A negligência das questões institucionais, organizacionais e processuais é superada mediante o surgimento de duas ordens de condições, quais sejam, as teóricas (relativas ao desenvolvimento de perspectivas teórico-metodológicas referentes ao desenvolvimento da Sociologia das Organizações, da Ciência Política e da Antropologia do Direito, que permitem a realização de estudos sobre a estrutura, organização e sobre a forma como são estabelecidos os espaços de decisão entre os operadores do direito, assim como sobre a dinâmica do sistema judiciário acerca da importância dos processos e das instituições) e as condições sociais. No que tange às condições sociais, o autor destaca a importância dos movimentos e lutas sociais na produção de novas problemáticas sociais (que passam a alterar a dinâmica do sistema judiciário) e a emergência da crise da administração da justiça. Esta crise é produto da expansão das lutas sociais, que levam à consolidação do Estado-Providência; por consequência, os direitos sociais foram expandidos e os extratos sociais de trabalhadores foram integrados às dinâmicas de consumo, até então fora de seu alcance. Desse modo,

[...] esta integração [...] implicou que os conflitos emergentes dos novos direitos sociais fossem constitutivamente conflitos jurídicos cuja dirimição caberia em princípio aos tribunais, litígios sobre a relação de trabalho, sobre a segurança social, sobre a habitação, sobre os bens de consumo duradouros, etc. (Santos, 2010, p. 165).

Essas condições teóricas e sociais tornaram possíveis o desenvolvimento de diversos estudos, cujo objetivo principal era aprofundar as interações (bastante complexas) entre o direito processual e a administração da justiça, levando em consideração o contexto social e econômico em que operam.

Diante desse quadro, a atual crise do sistema judiciário não depende somente dos problemas relacionados ao sistema previden- 
ciário e à desestabilização das economias nacionais, com a ascensão da globalização. Ela está relacionada com a ascensão de novas exigências da sociedade civil, que privilegiam os mecanismos de democratização da justiça e o controle externo sobre os operadores do direito, seja quanto à magistratura, ao ministério público ou à polícia.

Desse modo, as diferenças sociais passam a constituir novas demandas sociais, cuja concretização é buscada por intermédio da justiça. Tal concretização dos direitos depende, segundo o autor, do modo como os indivíduos acessam a justiça, a qual varia de acordo com as instâncias sociais pelas quais os agentes sociais transitam.

Ao investigar os obstáculos ao acesso efetivo à justiça, Santos (2010) observa que ocorre uma tripla vitimização das classes populares, visto que o sistema jurídico é acionado distintamente pelos estratos sociais. Esses obstáculos são econômicos, sociais e culturais:

- Econômicos porque os custos dos litígios são muito elevados, visto que "... a relação entre o valor da causa e o custo da litigação aumenta à medida que baixa o valor da causa" (Santos, 2010, p. 168); soma-se a esta questão a lentidão dos processos, que onera ainda mais a ação judicial.

- Social porque os agentes sociais que detêm menores recursos financeiros tendem a conhecer pior os seus direitos e, por consequência, “... a ter mais dificuldades em reconhecer um problema que os afecta como sendo problema jurídico" (Santos, 2010, p. 170);

- Cultural porque mesmo que os indivíduos reconheçam um problema como sendo jurídico, isto é, como sendo de violação de seus direitos, é necessário que eles se disponham a interpor a ação, ou seja, recorrer aos tribunais para solucionar o problema encontrado.

Desse modo, para o autor, quanto menor a renda e mais baixo o extrato social dos indivíduos maior é sua distância do sistema judiciário; esse distanciamento implica no desconhecimento de operadores de direitos como advogados, por exemplo, assim como no afastamento geográfico entre o lugar em que esses indivíduos vivem e/ou traba- 
lham e o local da cidade onde se encontram os escritórios de advocacia, as delegacias e os fóruns.

Se formalmente os indivíduos são percebidos como iguais perante a lei, as situações fáticas analisadas permitem identificar a desigualdade da regra formal perante os agentes sociais. Esta perspectiva é identificada nos casos que envolvem situações de violência conjugal contra a mulher, nas quais, não necessariamente, a vítima da agressão busca uma condenação formal do acusado no sistema de justiça.

As lógicas e diferentes racionalidades que cercam os agentes sociais envolvidos em situações de violência doméstica e/ou familiar não necessariamente condizem com as respostas e soluções apresentadas pelos tribunais; elas requerem, na maior parte das vezes, mecanismos alternativos para a sua resolução e prevenção, que não estejam somente vinculados à ordem penal vigente.

Desse modo, se por um lado a Lei Maria da Penha é um produto político dos movimentos sociais, que lutam pelo reconhecimento dos direitos das mulheres em todas as esferas da vida social (Rifiotis, 2008), por outro, sua aplicação prática tem enfatizado basicamente seu caráter punitivo, em detrimento da proteção e prevenção.

\section{A RACIONALIDADE DO DIREITO MODERNO E O PRO- CESSO DE JUDICIARIZAÇÃO DAS RELAÇÕES DE VIO- LÊNCIA CONJUGAL CONTRA A MULHER}

As mudanças sociais observadas nas últimas décadas implicam, segundo Locheet al. (1999), diferentes conflitos e formas de sociabilidade, que passam a ser orientados cada vez mais pelo princípio democrático e participativo. Neste sentido,

[...] a cidadania [...] significa um tipo de sociabilidade que busca não a harmonia nem a valorização da etiqueta social, mas sim a inteligibilidade das ações individuais, na medida em que tais ações são concebidas em um espaço social público e participativo: isto é, como princípio de reciprocidade em uma sociedade que assume a democracia como valor fundamental (Locheet al., 1999, p. 45). 
Deste modo, o problema central que se apresenta tanto para o sistema judiciário como para a sociedade civil e para o próprio Estado não corresponde ao fato de justificar os direitos políticos e sociais conquistados pelos indivíduos ao longo do século passado; a questão que se delineia diz respeito às formas encontradas para garantir a efetividade desses direitos, sejam eles relativos às questões de gênero, habitação, geracionais, ambientais, etc..

Esse processo se intensifica diante da abertura política no país, na década de 80, que é acompanhada por uma constante atuação dos movimentos sociais, em favor dos direitos dos indivíduos. Esta discussão é acompanhada pelo desejo de independência e de autonomia judicial, que é acatado pela Constituição de 1988.

De acordo com Sorj (2000), a sociedade moderna trouxe consigo a demanda por novos direitos, em torno dos quais passaram a se organizar os novos conflitos ideológicos e os novos movimentos sociais. Em torno deste processo, as demandas macrossocietárias e os sistemas de leis, juntamente com o poder judiciário, passam a ser articulados pelos conceitos de juridificação (ou judiciarização) e judicialização².

A noção de direito, para este autor, e as interpretações sobre ele, estão relacionadas idiossincraticamente com o entendimento de cada processo histórico. Estas percepções valorizam determinados grupos sociais e situações como é o caso das minorias étnicas e sexuais na contemporaneidade.

Como consequência destas transformações societárias, que colocam em discussão os valores e os problemas enfrentados na contemporaneidade, passam a convergir para o judiciário conflitos até então discutidos e solucionados em outras instâncias sociais. Os problemas que surgem a partir desta reconfiguração do papel do sistema judiciário estão relacionados ao fato de que,

[...] na medida em que a juridificação da sociedade se constrói pela transferência para o judiciário dos conflitos sociais que não encon-

\footnotetext{
2 Segundo Habermas, o conceito de juridificação [ou judiciarização] está relacionado à crescente regulação do Estado sobre as relações sociais, que passam a ser controladas e disciplinadas pela sua intervenção interna e constante burocratização; a judicialização, por sua vez, diz respeito à crescente difusão dos métodos judiciais sobre a política e o conflito social, inclusive quanto às ações do Executivo e do Legislativo (Sorj, 2000).
} 
tram canais de solução nos sistemas tradicionais de representação (Executivo e Legislativo), ela modifica a relação entre os poderes, gera a crescente politização do Judiciário e afeta a sua capacidade de funcionamento como poder responsável pela aplicação das leis, aumentando seu campo de arbítrio, criando um potencial de tensão e rompimento com o sistema representativo. Se no capitalismo o Judiciário teve como função central integrar a sociedade, transformando em universais certos valores e despolitizando os conflitos em torno deles, a juridificação da sociedade politiza o Judiciário e retira seu caráter apolítico e sua força integradoras (Sorj, 2000, p. 112).

Quanto à sociedade brasileira, a sua judiciarização manifesta-se como um "substitucionismo", por meio do qual se supõe que as respostas e soluções para a desigualdade social, étnica e de gênero, etc., possam ser encontrados no Poder Judiciário. Por consequência, este fator gera um problema para esta instituição, pois ela passa a ser pressionada por novas demandas de serviço, que complexificam cada vez mais seu campo de atuação.

Dentre essas demandas, destacam-se as ações dos movimentos sociais de combate e prevenção à violência doméstica contra a mulher que enfatizam as estratégias de luta contra a violência conjugal a partir da judiciarização das relações sociais. Ao mesmo tempo em que o sistema de justiça passa a receber e responder formalmente aos litígios relativos à violência conjugal, tendo como base a criminalização dessa forma de violência e a punição do acusado da agressão (fator que atribuiria poder e direitos para as mulheres), nem todos os conflitos que as mulheres apresentam para o sistema de justiça, principalmente, no espaço das delegacias (especializadas ou não) são passíveis da aplicação das medidas previstas na Lei 11.340/2006.

Ao abordar a questão da judiciarização, Rifiotis (2008) salienta que é importante,

[...] destacar que se trata de uma passagem de uma leitura centrada na 'violência' para outra focada no direito. Neste processo, sendo a Delegacia da Mulher um serviço de polícia judiciária, uma correia 
de transmissão entre a identificação, o processamento de práticas criminais e o poder judiciário, é fundamental refletir sobre o descompasso entre os objetivos institucionais e a estratégia política subjacente (Rifiotis, 2008, p. 228).

Desse modo, o processo de judiciarização da violência conjugal remete a um debate sobre as características e limitações encontradas no encaminhamento desses litígios. Ao mesmo tempo em que as delegacias da mulher constituem-se em um espaço que tem por objetivo estabelecer práticas sociais concretas em relação à violência conjugal, buscando formalmente a aplicação de medidas punitivas para situações de agressão e transgressão dos direitos das mulheres, por outro lado observam-se apropriações distintas dessas instituições por parte das mulheres vítimas de violência doméstica. Essas apropriações dizem respeito às representações sociais sobre os significados de "fazer justiça" e "entrar na justiça", isto é, não necessariamente as mulheres que registram uma ocorrência policial na delegacia de proteção à mulher desejam representar formalmente contra seus companheiros ou ex/companheiros.

Para Rifiotis (2008) os espaços das delegacias da mulher e dos Juizados Especiais Criminais (responsáveis pelos litígios de violência conjugal no Brasil, antes da promulgação da Lei Maria da Penha) não produziram, enquanto instâncias judiciarizantes, efeitos esperados no que se refere ao empoderamento das mulheres nas situações de violência conjugal.

Do mesmo modo, diante dos dados que serão apresentados no presente estudo, o caráter penal (em detrimento da perspectiva protetiva e preventiva) até então apresentado pela Lei 11.340/2006, em relação ao encaminhamento dos casos que entram no fluxo do sistema judiciário, não apresenta resultados satisfatórios e esperados na diminuição dos índices de violência doméstica contra a mulher. Se por um lado observa-se um aumento significativo no registro das ocorrências que envolvam esta forma de violência a partir de setembro de 2006, por outro, isso não significa necessariamente que o sistema judiciário esteja respondendo satisfatoriamente às demandas apresentadas pelas mulheres que procuram por esta instituição. 
Como afirma Azevedo (2011), mesmo diante das diferentes interpretações ${ }^{3}$ em torno da lei 11.340/2006, é preciso estabelecer uma análise crítica sobre as reais transformações ocasionadas por esta legislação.

A primeira mudança refere-se à redução da margem para conciliação entre as partes envolvidas em situações de violência conjugal, visto que ao se excluir a violência doméstica da Lei 9.099/95, os delitos deste tipo são tratados pelos juizados comuns, concorrendo com outros crimes no encaminhamento e tratamento dado pelo sistema judiciário. Embora a legislação específica oriente, minunciosamente, a atividade dos operadores de direito, pesquisas tem identificado “... as dificuldades existentes, tanto estruturais quanto culturais, para que esses delitos venham a receber por parte da Polícia o tratamento adequado" (Azevedo, 2011, p. 13). Estas dificuldades são agravadas naqueles municípios e regiões em que não existe uma delegacia especializada de proteção à mulher, conforme pode ser verificado no trabalho de campo e apresentada na discussão dos resultados.

A segunda mudança ocorre quando a Lei Maria da Penha concede amplo poder aos magistrados para orientar suas decisões de acordo os seus próprios critérios. Tal discricionariedade pode ser observada no que tange à prisão preventiva como medida protetiva de urgência. Para Sabadell (2008) o sistema judiciário perpetua de alguma forma as desigualdades entre homens e mulheres, apresentando limitações na resolução do problema; esta limitação faz referência à estrutura positiva do Direito, que se propõe a uma decisão objetiva que, não necessariamente, resolve satisfatoriamente o problema vivenciado pelas mulheres vítimas de violência conjugal, ou seja,

[...] a Justiça, ao julgar os casos que lhe são apresentados, pauta-se não apenas pelo crime e pela presença de elementos que comprovem sua ocorrência (autoria, materialidade e os vínculos pertinentes a

3 Para Azevedo (2011) "Nas pesquisas realizadas sobre o funcionamento dos JECrim [Juizado Especial Criminal], não há, no entanto, um consenso sobre o significado de sua implantação para o equacionamento judicial da violência de gênero. Alguns perceberam os JECrim como benéficos à luta das mulheres por darem visibilidade ao problema da violência de gênero, que antes não chegava ao âmbito judicial em virtude da obrigatoriedade do inquérito policial, que acabava não sendo realizado. Outros entenderam que os Juizados ampliaram a rede punitiva estatal, judicializando condutas que antes não chegavam até o Judiciário, mas em muito pouco contribuíram para a diminuição do problema da violência conjugal, pela impunidade decorrente da banalização da alternativa da cesta básica" (12). 
esses dois aspectos), mas por motivações extralegais que se referem aos comportamentos sociais das vítimas e de seus agressores. Em relação aos casos que envolveram conflitos de gênero, os papéis sociais são sempre referenciados às instituições família e casamento e aos aspectos definidores desses papeis sociais nessas instâncias: sexualidade feminina e trabalho masculino (Izumino, 2004, p. 268).

Embora Weber (1995) e Rifiotis (2008) apresentem a instância jurídica, isto é, o direito, como a principal forma de legitimidade na sociedade moderna, devido à crença estabelecida na legalidade, é preciso observar, como bem apresenta Bourdieu (2005) e Sousa (2010), que o espaço judicial constitui-se em uma instância particularizada, munida de um lógica e linguagem particulares, apresentando-se muitas vezes muito mais como um espaço de disputa concorrencial do direito de definir publicamente o que é o direito. Diante das dinâmicas internas apresentadas pelo campo jurídico e pelos aspectos histórico-sociais que estruturam o direito moderno observa-se que nem sempre o sistema de justiça apresenta-se como um espaço que priorize a emancipação e o exercício da cidadania dos agentes sociais.

Ao contrário, o acesso ao sistema judiciário implica mudanças tanto institucionais (no que diz respeito ao conjunto de normas formais e políticas públicas e sociais) quanto sociais e culturais (referentes às percepções sobre os papéis sociais que homens e mulheres desempenham na sociedade).

Tais elementos implicam no fato de que o arcabouço jurídico que orienta as formas dos indivíduos se conduzirem na sociedade está diretamente ligado à moralidade que impera em uma dada sociedade, assim como às pressões e articulações políticas organizadas pelos movimentos sociais (neste caso, grupos de mulheres que buscam reconhecimento político e social). 


\section{CARTOGRAFIA DA VIOLÊNCIA CONJUGAL CONTRA A MULHER}

A violência contra a mulher é um fenômeno que está presente em todas as épocas e lugares. No entanto, os índices e características desta problemática social podem variar regionalmente, dependendo de vários aspectos, dentre os quais, pode-se mencionar a mobilização e atuação dos movimentos sociais, a moralidade que orienta as formas de pensar e agir dos indivíduos, etc.

Para fins desta pesquisa o recorte de universo utilizado procurou reunir informações de regiões cartográficasdistintas: norte e centro do Rio Grande do Sul e fronteira Brasil-Uruguai.

A coleta de dados foi realizada entre os anos de 2012 e 2013, nas respectivas delegacias de proteção à mulher. A distribuição das ocorrências ao longo dos anos pesquisados pode ser observada na tabela abaixo. Salienta-se que o recurso metodológico utilizado contemplou a coleta das informações um ano antes da promulgação da Lei Maria da Penha no Brasil, tendo por objetivo analisar a aplicação da Lei de Violência Doméstica no Uruguai em comparação com a Lei Maria da Penha no Brasil e, portanto, delimitou os anos entre 2005 e 2009 para analisar as ocorrências.

Quadro 01 - Número de ocorrências policiais analisadas

\begin{tabular}{|c|c|c|c|c|c|}
\hline & 2005 & 2006 & 2007 & 2008 & 2009 \\
\hline Santa Maria & 100 & 343 & 232 & 361 & 154 \\
\hline Erechim & - & - & - & - & 121 \\
\hline Santana do Livramento & - & 66 & 296 & 343 & 333 \\
\hline Rivera & 813 & 800 & 840 & 259 & 64 \\
\hline
\end{tabular}

Fonte: elaboração própria.

$\mathrm{Na}$ cidade de Erechim os dados coletados referem-se somente ao ano de 2009, visto que a Delegacia de Proteção à Mulher começou suas atividades no mês de abril daquele ano. A cidade de Sant'Ana do Livramento diferenciou-se na coleta dos boletins de ocorrência, pelo fato de não haver uma Delegacia da Mulher, mas sim um cartório, o que dificultou o acesso às informações, sendo necessária a mediação 
da pessoa responsável pelo registro das ocorrências das mulheres da respectiva instância. Sendo assim, o levantamento foi realizado pela responsável pelo Cartório de Atendimento à Mulher, que repassou os dados desde o ano de 2006 (novembro e dezembro) até 2009.

A ausência de uma instância especializada contribui significativamente para um inadequado tratamento da violência conjugal por parte dos operadores de direito, visto que em suas ações cotidianas eles reproduzem de alguma forma ou de outra as representações valorativas em torno das categorias homem, mulher, família, etc. Estas problemáticas tornam-se visíveis tanto no atendimento às vítimas de violência conjugal quando na organização dos dados dos registros de ocorrência, conforme pode ser observado no município de Santana do Livramento/RS. O município não possui uma delegacia especializada de atendimento à violência doméstica ou violência de gênero. A estrutura existente na cidade conta apenas com um Cartório de Atendimento à Mulher na Delegacia de Polícia Civil. Durante as visitas realizadas à respectiva instituição foi possível observar a inexistência de um espaço apropriado para o atendimento às mulheres vítimas de violência doméstica ou violência de gênero; o Cartório está localizado em uma pequena sala, espaço que não permite um adequado atendimento, visto que os depoimentos da vítima podem ser ouvidos pelas pessoas que transitam pela instituição. Do mesmo modo, a respectiva delegacia não permitiu à equipe de pesquisa o acesso direto aos boletins de ocorrência; os dados obtidos foram fornecidos pelo próprio cartório

O mapa a seguir expõe a distribuição geográfica das cidades pesquisadas no mapa do estado do Rio Grande do Sul e apresenta o tipo de violência que apareceu com maior frequência em cada cidade. Percebe-se que as cidades de Santa Maria e Erechim apresentam a "ameaça" como natureza do fato de maior ocorrência. Diferentemente, na cidade de Sant'Ana do Livramento a "lesão corporal" foi o tipo de violência que apareceu com maior frequência. 


\section{Imagem 1 - Natureza do fato de maior ocorrência em cada cidade}

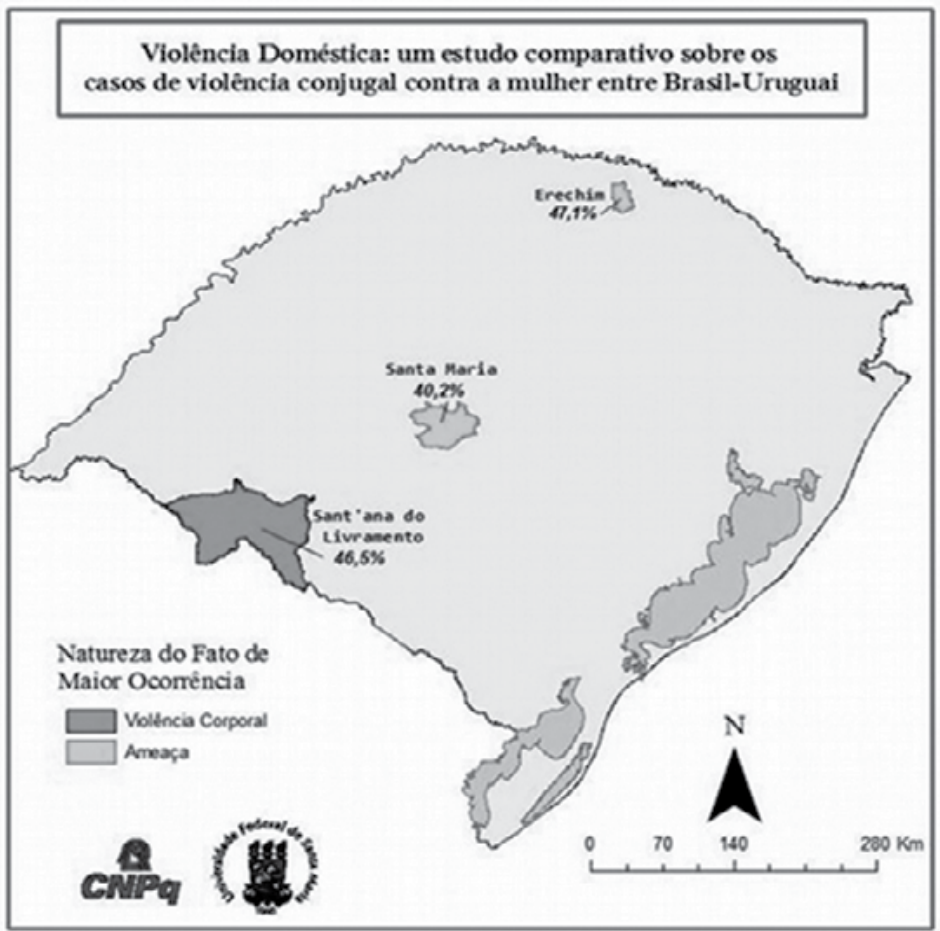

Fonte: elaborado no programa ArcGis a partir dos dados coletados na pesquisa

Durante o procedimento de coleta de dados percebeu-se que o delito que é mais denunciado pelas mulheres vítimas de violência conjugal é a "ameaça". No entanto, elas não costumam representar criminalmente contra este tipo de violência por receio de que a ameaça se efetive em lesão corporal ou mesmo em homicídio. Em contrapartida, o delito que mais condiciona as mulheres a optarem pela punição do agressor é a lesão corporal. Nesse sentido, são registrados mais Boletins de Ocorrência de casos de ameaça e gerados mais Inquéritos Policiais de casos de lesão corporal.

Esta observação indica que a violência contra a mulher apresenta características semelhantes nas distintas regiões pesquisadas. Sendo assim, percebe-se que independentemente das características 
particulares das cidades pesquisadas, esta violência está presente de forma análoga nelas.

Quando se analisa a distribuição dos crimes por bairros das cidades, percebe-se uma dispersão de número de casos em cada bairro. No mapa a seguir vê-se a distribuição dos bairros da cidade de Santa Maria com uma escala de cores conforme o número de ocorrências de violência conjugal contra a mulher.

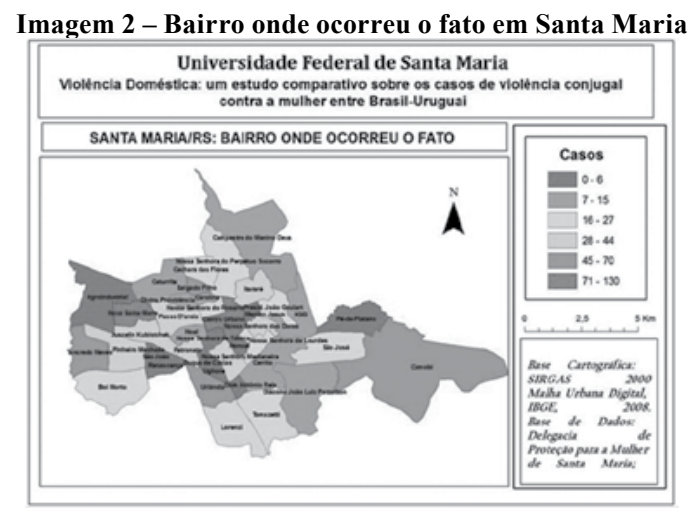

Fonte: elaboração no programa ArcGis a partir dos dados coletados na pesquisa

A análise do mapa de Santa Maria permite identificar os bairros que apresentam os maiores índices de violência conjugal contra mulher, dentre os quais se destacam os seguintes: Centro, com 130 casos e Nova Santa Marta, com 91 casos, seguidos pelos bairros Camobi, Salgado Filho, Tancredo Neves e Urlândia, com 70, 63, 56 e 51 casos respectivamente.

Os bairros que apresentam o maior número de ocorrências possuem características socioeconômicas distintas, o que permite verificar que a violência conjugal contra a mulher é um fenômeno que está presente em todo espaço urbano de Santa Maria, independente das particularidades de cada região.

Paralelamente, conforme a imagem a seguir, na cidade de Erechim o bairro que concentra o maior número de ocorrências de violência conjugal contra a mulher é o Centro, com 24 casos. Os bairros que o seguem têm números de ocorrências destacavelmente 
inferiores. O bairro Três Vendas apresenta 8 casos, enquanto os bairros Progresso e Cristo Rei possuem 7 ocorrências cada um.

\section{Imagem 3 - Bairro onde ocorreu o fato em Erechim}

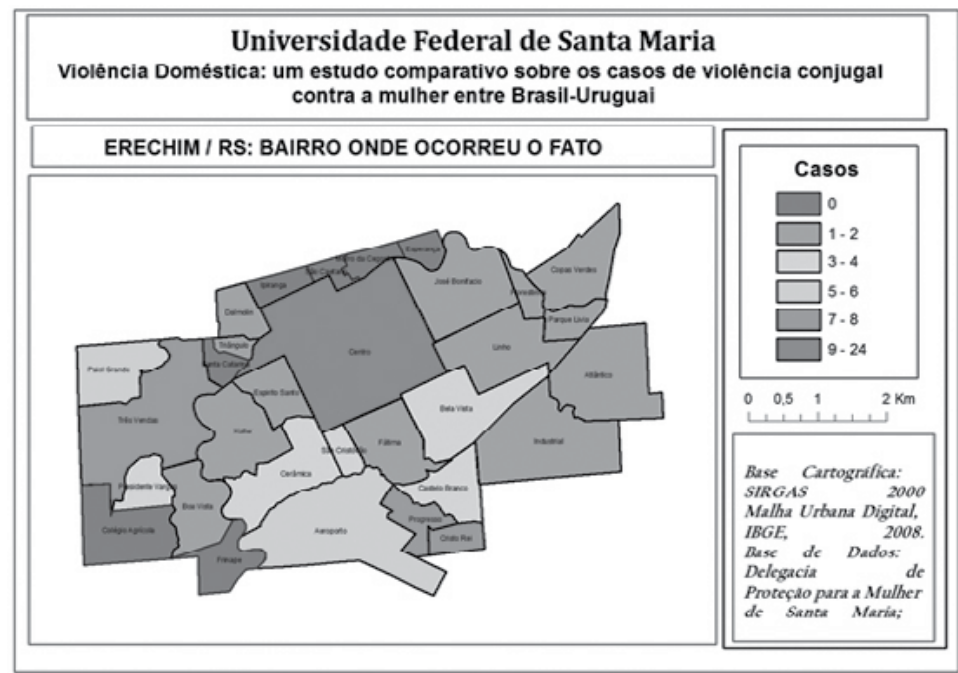

Fonte: elaboração no programa ArcGis a partir dos dados coletados na pesquisa

Tendo como base a distribuição cartográfica das situações de violência contra a mulher, os bairros das cidades de Santa Maria e Erechim que apresentam os índices mais elevados de ocorrências de violência conjugal contra a mulher são os bairros centrais. Isto não significa necessariamente que nestes bairros há mais casos de violência conjugal contra a mulher, mas sim que estes delitos chegam mais frequentemente à esfera judicial. Sendo assim, como as delegacias estão localizadas nestas regiões, é possível pensar que a localização geográfica da instituição é determinante no acesso das mulheres, vítimas de violência doméstica, ao sistema de justiça.

Este afastamento geográfico dos grupos populares da estrutura do sistema de justiça pode ser percebido através dos dados reunidos para esta pesquisa. Nas duas delegacias especializadas de proteção à mulher (nas cidades de Santa Maria e Erechim), que autorizaram o acesso aos arquivos institucionais, observou-se que os 
bairros que apresentaram os maiores índices de registro de boletins de ocorrência de violência conjugal contra a mulher são as regiões centrais das respectivas cidades, nas quais estas instâncias jurídicas estão localizadas.Com relação ao Uruguai, embora possua características distintas do Brasil, também sofre os mesmos problemas com relação à questão da violência doméstica. Nesse sentido, vale ressaltar que a Lei de Violência Doméstica no Uruguai, ao contrário da Lei Maria da Penha, possui uma abrangência maior, tendo em vista que estende a legislação específica a todos os membros do grupo familiar e não apenas à violência contra a mulher ou violência de gênero.

Nas Comisarías de la Mujer y la Família, as ocorrências aumentaram como um todo no Uruguai no decorrer dos anos pesquisados, conforme pode-se observar no gráfico abaixo.

\section{Gráfico 01 - Evolução de Denúncias de Violência Doméstica no Uruguai}
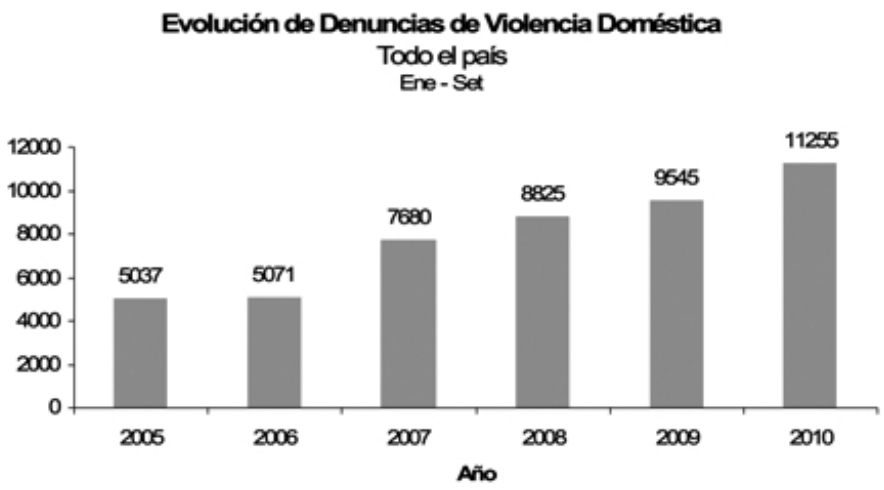

Fonte: Observatorio Nacional sobre Violencia y Criminalidad - Uruguay, 2010.

Ao contrário dos demais departamentos uruguaios, que apresentaram um crescimento significativo de denúncias de violência doméstica entre os anos de 2005 e 2009, Rivera tem apresentado a partir de 2008 um decréscimo significativo nos registros de boletins de ocorrência. 
Quadro 02 - Ocorrências formalizadas de violência doméstica

\begin{tabular}{|c|c|c|c|c|c|}
\hline $\begin{array}{c}\text { Violência } \\
\text { Doméstica }\end{array}$ & 2005 & 2006 & 2007 & 2008 & 2009 \\
\hline Rivera & 813 & 800 & 840 & 259 & 64 \\
\hline
\end{tabular}

Fonte: Relatório de Información pública sobre laintervencióndelMinisteriodel Interior ensituaciones de violencia doméstica, 2012: 19.

Cabe destacar que Rivera ${ }^{4}$ e Sant'Ana do Livramento são conhecidas como "Fronteira da Paz", o que garante o livre acesso dos agentes sociais entre uma cidade e outra. Esta característica local pode dificultar as denúncias referentes às realizações de ocorrências por parte das mulheres que sofrem violência, implicando, por consequência, no declínio dos registros policiais na cidade de Rivera.

Apesar da diferença do número de ocorrências entre as cidades pesquisadas e os seus respectivos bairros, faz-se necessário destacar que o mapeamento da violência conjugal contra a mulher permitiu verificar que esta violência está presente no cotidiano destas regiões, independente dos seus contextos socioeconômicos e culturais.

\section{LEI 11.340/2006 (LEI MARIA DA PENHA/BRASIL) E A LEI 17.514/2002 (LEI DE VIOLÊNCIA DOMÉSTICA/URUGUAI): UM ESTUDO COMPARATIVO ENTRE A EXPERIÊNCIA BRASILEIRA E URUGUAIA DE APLICAÇÃO DE MECA- NISMOS DE PROTEÇÃO À MULHER}

Apreender as especificidades da Lei Maria da Penha/Brasil e da Lei de Violência Doméstica/Uruguai requer um estudo das nuances que perpassam cada uma destas legislações, aqui observadas sob uma perspectiva sociológica.

Desse modo, para analisar os indicadores de violência conjugal nestes países é necessário ter presente que os dados coletados e publicados são produzidos de acordo com as fontes de informações oficiais,

4 O Cartório de Atendimento à Mulher de Sant'Ana do Livramento disponibilizou dados gerais sobre as ocorrências, sem a distribuição dos casos nos bairros do município, não sendo, portanto, possível realizar o mapeamento das ocorrências nesta cidade. Assim como em Riveira, já que esta informação também não consta no relatório "Información pública sobre laintervencióndel Ministeriodel Interior ensituaciones de violencia doméstica”. 
presentes em cada Estado. Da mesma forma, é preciso problematizar a cobertura e a qualidade desses dados, assim como os alcances e limites das fontes responsáveis pela sua produção e armazenamento.

É importante frisar que Brasil e Uruguai, desde a década de oitenta (período em que mundialmente se disseminam os movimentos de mulheres por igualdade de gênero) tem incorporado ações com o objetivo de promover as questões de gênero, seja através de políticas públicas e sociais, seja através de mudanças nas legislações nacionais.

As instâncias governamentais que tratam diretamente das questões de gênero e, por consequência, das situações relativas à violência doméstica/violência conjugal são:

Quadro 03 - Instâncias governamentais criadas para tratar das questões relativas à violência doméstica/violência conjugal no Brasil e Uruguai

\begin{tabular}{|c|c|c|}
\hline & $\begin{array}{l}\text { Mecanismos } \\
\text { governamentais }\end{array}$ & Características relativas à criação \\
\hline Brasil & $\begin{array}{l}\text { Secretaria de Políticas } \\
\text { para Mulheres - SPM }\end{array}$ & $\begin{array}{l}\text { 2003 - Medida Provisória 103: secretaria es- } \\
\text { pecial, vinculada à Presidência da República. } \\
2010 \text { - competência modificada pela Lei }{ }^{\circ} \\
\text { 12.314: torna-se instância definitiva da estru- } \\
\text { tura do governo federal. }\end{array}$ \\
\hline Uruguai & $\begin{array}{c}\text { Instituto Nacional das } \\
\text { Mulheres - INMU- } \\
\text { JERES }\end{array}$ & $\begin{array}{l}1987 \text { - Criado pelo decreto governamental o } \\
\text { Instituto Nacional da Família e da Mulher. } \\
2005 \text { - Lei no 17.930: instância integrada à } \\
\text { estrutura do Ministério do Desenvolvimento } \\
\text { Social. }\end{array}$ \\
\hline
\end{tabular}

Fonte: Adaptado da página 18, RELATÓRIO DIAGNÓSTICO REGIONAL. Indicadores sobre violência doméstica baseada em gênero no Mercosul, 2011. Disponível em www.mercosurmujeres.org. Acesso em 20 de julho de 2013.

De acordo com o relatório da Reunião Especializada de Mulheres do Mercosul (REM, 2011), "Indicadores de violência doméstica baseada em gênero no Mercosul", a estrutura governamental disponibilizada para atendimento da violência doméstica contra a mulher até o ano de 2010 no Brasil e Uruguai respectivamente é:

a. Brasil: 22 estados e mais de 200 municípios já disponibilizavam de algum tipo de secretaria ou coordenadoria que trabalhava diretamente com as questões de gênero. 
b. Uruguai: as instâncias de gênero estão representadas em 10 departamentos e de uma secretaria da mulher, na cidade de Montevidéo, criada em 1992.

No que tange às legislações nacionais, relativas à especificidade da prevenção da violência contra a mulher, o Uruguai aprovou no ano de 2002 a Lei 17.514 (Lei de Violência Doméstica), enquanto o Brasil promulgou somente no ano de 2006 a Lei Maria da Penha. No quadro 4 é possível observar as medidas previstas, público-alvo, definição de violência e tipificação que as legislações do Brasil e Uruguai adotaram para às situações de violência doméstica/conjugal.

Quadro 4 - Características das legislações de proteção às mulheres em situação de violência doméstica/violência conjugal no Brasil e Uruguai

\begin{tabular}{|c|c|c|}
\hline & Brasil & Uruguai \\
\hline $\begin{array}{l}\text { Regramento } \\
\text { formal } \\
\text { especial }\end{array}$ & $\begin{array}{l}\text { Lei 11.340/2006 - Lei Maria da Pe- } \\
\text { nha }\end{array}$ & $\begin{array}{l}\text { Lei } 17.514 / 2002-\text { Lei de } \\
\text { Violência Doméstica }\end{array}$ \\
\hline $\begin{array}{l}\text { Medidas pre- } \\
\text { vistas } \\
\text { na legislação }\end{array}$ & Abrange as esferas civil e penal & $\begin{array}{l}\text { Aplicação de medidas caute- } \\
\text { lares (cíveis) às situações de } \\
\text { natureza não delitiva. } \\
\text { Há o agravante da pena para } \\
\text { as situações em que vítimas } \\
\text { são mulheres. }\end{array}$ \\
\hline Público alvo & $\begin{array}{l}\text { Aplicada exclusivamente para casos } \\
\text { em que as vítimas são mulheres }\end{array}$ & $\begin{array}{l}\text { Estendida a todos os mem- } \\
\text { bros do grupo doméstico e/ } \\
\text { ou familiar. }\end{array}$ \\
\hline $\begin{array}{l}\text { Definição } \\
\text { da violência }\end{array}$ & $\begin{array}{l}\text { "Para efeitos desta lei, configura vio- } \\
\text { lência doméstica e familiar contra } \\
\text { a mulher qualquer ação ou omissão } \\
\text { baseada em gênero que lhe cause } \\
\text { morte, lesão, sofrimento físico, se- } \\
\text { xual ou psicológico e dano material } \\
\text { ou patrimonial: I - no âmbito da uni- } \\
\text { dade doméstica, compreendida como } \\
\text { o espaço de convívio permanente de } \\
\text { pessoas, com ou sem vínculo fami- } \\
\text { liar, inclusive as esporadicamente } \\
\text { agregadas; II - no âmbito da família, } \\
\text { compreendida como a comunidade } \\
\text { formada por indivíduos que são ou } \\
\text { se consideram aparentados, unidos } \\
\text { por laços naturais, por afinidade ou } \\
\text { por vontade expressa; III - em qual- } \\
\text { quer relação íntima de afeto, na qual o } \\
\text { agressor conviva ou tenha convivido } \\
\text { com a ofendida, independente da coa- } \\
\text { bitação" (Art. 50, Lei 11.340/2006). }\end{array}$ & $\begin{array}{l}\text { "Constituye violencia domés- } \\
\text { tica toda acción u omisión, } \\
\text { directa o indirecta, que por } \\
\text { cualquier medio } \\
\text { menoscabe, limitando ilegíti- } \\
\text { mamente el libre ejercicio o } \\
\text { goce de los derechos huma- } \\
\text { nos de una persona, causada } \\
\text { por otra con la cual tenga o } \\
\text { haya tenido una relación de } \\
\text { noviazgo o con la cual tenga } \\
\text { o haya tenido una relación } \\
\text { afectiva basada en la cohabi- } \\
\text { tación y originada por paren- } \\
\text { tesco, por matrimonio o por } \\
\text { unión de hecho" (Art. } 2^{\circ} \text {, Lei } \\
17.514 / 2002 \text { ). }\end{array}$ \\
\hline
\end{tabular}




\begin{tabular}{|l|l|l|}
\hline & $\begin{array}{l}\text { São consideradas formas de violên- } \\
\text { cia doméstica ou familiar contra a } \\
\text { mulher: }\end{array}$ & $\begin{array}{l}\text { São consideradas formas de } \\
\text { violência: } \\
\text { Violência física; }\end{array}$ \\
Violência física; & Violência psicológica ou \\
Tipifica ação violência & Violência sexual; & Violência psicológica; \\
& Violência moral; & Violência sexual; \\
& Violência patrimonial. & Violência patrimonial. \\
\hline
\end{tabular}

Fonte: Adaptado da página 22, RELATÓRIO DIAGNÓSTICO REGIONAL. Indicadores sobre violência doméstica baseada em gênero no Mercosul, 2011. Disponível em www.mercosurmujeres.org. Acesso em 20 de julho de 2013.

Mesmo que a legislação brasileira esteja adequada às diretrizes apresentadas pela Convenção de Belém do Pará ${ }^{5}$ e “[...] seja a primeira da região [Mercosul] a adotar a perspectiva de gênero, reconhecendo que esta violência constitui uma violação de direitos humanos" (REM, 2011, p. 21) apresenta limitações.

O primeiro obstáculo encontrado pela Lei Maria da Penha, no que diz respeito a sua operacionalização, refere-se ao fato de que a proteção da mesma restringe-se às situações de violência contra a mulher vivenciadas somente no espaço doméstico e familiar.

O segundo entrave faz referência ao fato de que esta legislação somente pode ser aplicada para mulheres que sofreram alguma forma de violência doméstica/familiar ou de gênero, não estendendo a sua proteção aos demais membros da família ${ }^{6}$.

Embora movimentos sociais e grupos sociais, que pautam seus discursos na luta pelo reconhecimento da mulher na sociedade, apresentem dados e afirmem a importância da presença de espaços especializados no atendimento de mulheres que sofreram alguma

5 O Informe Hemisférico de Seguimento da Implementação da Convenção de Belém do Pará ressalta os problemas decorrentes da não diferenciação entre violência doméstica/e familiar e a violência de gênero. Estes problemas derivam da: “i) sua inadequação em face das recomendações da Convenção de Belém do Pará, que considera também outras práticas de violência, como a violência sexual, o tráfico de mulheres, a tortura e outras formas de violência praticada por agentes do Estado ou por ele tolerada; ii) a carga cultural, reprodutora de discriminação contra as mulheres, presente nestas categorias; iii) a exclusão da violência que é praticada por parceiros íntimos, mas que não compartilham do espaço doméstico com a vítima, nem possuem uma relação de vínculo formal; iv) a proteção de todos os membros da família, independente de sexo, contribuindo para o mascaramento da especificidade da violência baseada em gênero; v) leis amplas e sem a perspectiva de gênero, que permitem que sua aplicação se dê tanto para a criminalização de homens quanto de mulheres, violando a previsão do artigo $7^{\circ}$ da Convenção de Belém do Pará" (apud relatório REM, 2011, p. 26).

6 No que tange ao Brasil o problema é agravado quando, diante das características etárias das vítimas de violência conjugal, as mesmas são encaminhadas para outras delegacias especializadas como, por exemplo, a Delegacia de Proteção da Criança e do Adolescente e a Delegacia do Idoso. Este tratamento, definido por medidas formas e legais previstas nos códigos brasileiros, pulveriza ainda mais os dados relativos a esta forma de violência, trazendo, por consequência, dificuldades na elaboração de políticas públicas e sociais que atendam satisfatória e eficazmente este grupo social. 
forma de violência, é preciso salientar que o contexto que envolve todo o processo de violência doméstica, familiar e/ou conjugal traz implicações que afetam não apenas mulheres, como também crianças ${ }^{7}$, adolescentes, idosos, homens, etc.

Desse modo, devido à estrutura do sistema de justiça disponível no Brasil, observa-se que parcelas da população não conseguem garantir sua proteção através da lei 11.340/2006, limitando, por consequência, a aplicação desta legislação.

Além do mais, é salutar destacar que mesmo sendo considerada como sendo a legislação mais avançada e adequada às convenções internacionais, quando comparada às regras formais dos demais países latino-americanos da região, a mesma apresenta limitações. Ora, pensar que as problemáticas de gênero, de violência doméstica, familiar ou conjugal são resolvidas e minimizadas com a promulgação de uma legislação nacional é um equívoco, mais ainda quando a mesma regra não consegue ser efetivada completamente ${ }^{8}$.

Mudanças concretas no que tange a esta problemática demandam ações muito mais complexas e intensas, pois requerem transformações de ordem valorativa, institucional, estrutural e geracional. Sem estas alterações e ressignificações a aplicação da regra formal torna-se limitada e ineficaz'.

7 As situações de violência doméstica perpassam as questões geracionais e de gênero. Ao comparar os dados deste estudo com pesquisa anterior sobre violência doméstica contra crianças na cidade de Santa Maria é possível observar alguns indicadores que permitem pensar o quão complexa é esta forma de violação dos direitos humanos. A análise dos dados sobre violência doméstica contra crianças permitiu também identificar os bairros que apresentam os maiores índices deste conflito, quais sejam: Nova Santa Marta com 44 casos, Camobi com 44, Centro com 38, Salgado Filho com 38 e o bairro Pinheiro Machado com 33. Na maior parte destes bairros a situação da violência doméstica vitimiza tanto mulheres quanto crianças, sendo estes últimos as maiores vítimas dos delitos de lesão corporal $(23,8 \%)$, ameaça $(10,1 \%)$ e maus tratos $(8,7 \%)$. Contudo, é importante destacar que em relação a violência doméstica contra crianças os responsáveis pela agressão são tanto mães $(30,9 \%)$ quanto os pais $(22 \%)$. Estes indicadores empíricos remetem aos pressupostos teórico-metodológicos apresentados por Pierre Bourdieu (2005), para quem a dominação masculina e a violência simbólica estão incrustadas nos corpos dos agentes sociais de tal forma que os mesmos as repetem cotidianamente de forma naturalizada, reproduzindo através do processo de socialização as dinâmicas de poder e diferenciação social entre homens e mulheres.

8 Destaca-se aqui a ênfase na criminalização da violência em detrimento da proteção e prevenção, instâncias ainda não efetivadas após sete anos da vigência da lei.

9 As limitações encontradas na operacionalização da legislação dizem respeito ao "espaço de possíveis" presente no momento da aplicação da regra, isto é, à possibilidade desta regra ser interpretada e influenciada, de alguma forma, pelas categorias, enunciados e moralidade extralegais. Em outras palavras, o espaço de possíveis corresponde a um corpus de precedentes reconhecidos entre os quais a solução jurídica pode ser buscada, “... é o que fundamenta racionalmente uma decisão que pode-se inspirar, na realidade, em princípios diversos, mas que ela faz aparecer como produto de uma aplicação neutra e objetiva de uma competência especificamente jurídica" (Bourdieu, 2005, p. 231). 


\section{CONSIDERAÇÕES FINAIS}

A complexidade das sociedades contemporâneas desencadeou um processo de mudança social, por meio do qual foram (re) configuradas as relações interpessoais entre os indivíduos, seja no ambiente de trabalho ou nas diversas relações sociais que ocorrem em espaços públicos e/ou privados.

Se por um lado, foram estendidos formalmente a estes indivíduos uma série de direitos sociais, considerando-os iguais perante a lei, por outro lado, esta equidade não foi (e ainda não continua sendo) percebida na prática social, uma vez que o Estado, e a própria sociedade, não conseguem operacionalizá-la, devido à crise estrutural e as características de ordem moral com a qual se deparam. A exclusão destes direitos sociais para parcelas significativas da população (dentre elas para mulheres vítimas de violência conjugal e/ou violência doméstica) faz emergir uma nova dinâmica social, marcada, principalmente, pelos constantes conflitos sociais e pelo desejo desses grupos e movimentos sociais em garantir o acesso a esses direitos.

É preciso frisar que o conflito tem um papel preponderante nas relações sociais, pois alimenta não somente a mudança social e o processo de interação entre os indivíduos como também promove a união, a comunicação entre eles e entre os grupos. Assim, não é possível falar em sociedades sem conflito. Este está presente em qualquer organização social, seja no trabalho, nas relações conjugais, familiares, na política, nas associações, nos processos jurídicos, etc. É a partir dos princípios de combate e de união que se dá a sua unidade, sendo a sociedade o resultado destas duas categorias de interação.

A violência, independentemente de suas características, vai ser um desdobramento deste conflito e é entendida como a tentativa de um indivíduo impor a sua vontade a outro, através do uso real ou simbólico da força. A fim de diferenciar as diversas faces que a violência assume no cotidiano das pessoas é preciso classificá-la em duas modalidades: a existência da violência racional, que abarca aqueles conflitos entre indivíduos desconhecidos como a criminalidade, por exemplo, e da violência ritualizada, que faz parte do 
cotidiano das pessoas, podendo ser encontrada nas relações de trabalho, na religiosidade e na família, principalmente nas situações de violência doméstica vivenciadas cotidianamente por mulheres, mas também por crianças, adolescentes, idosos e, também em certa medida, pelos próprios homens.

Diante dessa classificação, ressalta-se que as mulheres são submetidas a ambas as formas de violência, as quais se perpetuam no cotidiano social, pois (re)afirmam imagens e representações sociais sobre as formas dos agentes sociais se conduzirem na sociedade. Desse modo, as relações de violência com as quais essas mulheres se deparam são produtos de uma sociabilidade ancorada na desvalorização dos papéis sociais desempenhados por esta categoria social.

Este estudo, portanto, deixa muitas questões. Observa-se que na área da violência conjugal/violência doméstica contra a mulher ainda há muito para investigar em termos de pesquisa. No que diz respeito às leis especializadas de proteção à mulher percebe-se a sua não efetividade no combate e na redução dos índices de violação dos direitos humanos, principalmente no que tange às medidas de proteção e prevenção desta forma de conflito.

As dificuldades encontradas, no que tange à problemática deste estudo, não dizem respeito tão somente à legislação, mas correspondem às interpretações valorativas presentes na sociedade e a forma como a regra formal é aplicada pelos operadores do direito. Desse modo, a diminuição dos índices de violência conjugal contra a mulher depende de mudanças que vão muito além da implementação da Lei Maria da Penha ou da Lei de Violência Doméstica. Elas requerem transformações de ordem estrutural, cultural e moral.

\section{REFERÊNCIAS}

AZEVEDO, R. G.; CRAIDY, M. Conflitos de gênero no judiciário: A aplicação da Lei 11.340/2006 pelo Juizado da Violência Doméstica e Familiar de Porto Alegre/RS. In: AZEVEDO, R. G. Relações de Gênero e Sistema Penal: Violência e conflitualidade nos Juizados de Violência Doméstica e Familiar contra a mulher. Porto Alegre, EDIPUCRS, 2011. 
BOURDIEU, P. O poder simbólico. Rio de Janeiro: Bertrand Brasil, 2005.

CORRÊA, M. Morte em família: Representação jurídica de papéis sociais. Rio de Janeiro: Graal, 1983.

DEBERT, G. G.; OLIVEIRA, M. Os modelos conciliatórios de solução de conflitos e a violência doméstica. Cadernos Pagu, ano 29, pp. 305$337,2007$.

GREGORI, M. F. Cenas e queixas: um estudo sobre mulheres, relações violentas e a prática feminista. Rio de Janeiro: Ed. Paz e Terra; São Paulo: ANPOCS, 1993.

Informe Hemisférico de Seguimento da Implementação da Convenção de Belém do Pará. In: http://www.violenciamulher.org.br, acesso em 06 de maio de 2013.

Instituto Nacional de Geografia e Estatística. Bases Cartográficas Municipais. In: http://mapas.ibge.gov.br/bases-e-referenciais/ bases-cartograficas/malhas-digitais, acesso em 13 de julho de 2013.

IZUMINO, W. P. Justiça e Violência contra a mulher. São Paulo: FAESP/ Anna Blume, 2004.

BRASIL. Presidência da República. Lei n. 11.340, de 07 de agosto de 2006, Lei Maria da Penha.In: http://www.planalto.gov.br/ccivil/_Ato20042006/2006/Lei/ L11340.htm, acesso em 12 de janeiro de 2014.

Ley n ${ }^{\circ}$ 17.514, Violência Doméstica. In: http://www.parlamento.gub.uy/leyes /AccesoTextoLey.asp?Ley=17514\&Anchor=, acesso em 10 de julho de 2014.

LOCHE, A. et al. Sociologia jurídica: estudos de sociologia, direito e sociedade. Porto Alegre: Síntese, 1999.

OLESEN, V. L. Os feminismos e a pesquisa qualitativa neste novo milênio. In:DENZIN, N. K.; LINCOLN Y. S. (org). O planejamento da pesquisa qualitativa: teorias e abordagens. Porto Alegre: Artmed, 2006.

PREFEITURA MUNICIPAL DE ERECHIM. Divisão Municipal Urbana. In: http://www.pmerechim.rs.gov.br/pagina/385/mapa-de-erechim, acesso em 13 de julho de 2013.

PREFEITURA MUNICIPAL DE SANTA MARIA. Divisão Urbana. In: http://www.santamaria.rs.gov.br/escritorio/?secao=documentos, 
acesso em 13 de julho de 2013.

RELATÓRIO DIAGNÓSTICO REGIONAL. Indicadores sobre violência doméstica baseada em gênero no Mercosul, 2011. In: www. mercosurmujeres.org,scesso em 20 de julho de 2013.

Relatório Información Pública sobre laIntervencióndelMinisteriodel Interior em Situaciones de Violencia Doméstica, 2012. In: www. cainfo.org.uy, acesso em 20 de outubro de 2012.

RIFIOTIS, T. Judiciarização das relações sociais e estratégias de reconhecimento: repensando a 'violência conjugal' e a 'violência intrafamiliar'. Rev. Katálysis, Vol. 11, n 2, pp.225-236, 2008.

SABADELL, A. L. Manual de Sociologia Jurídica. 4 ${ }^{\mathrm{a}}$ Ed. São Paulo: Revista dos Tribunais, 2008.

SAFFIOTI, H. I. B.; ALMEIDA, S. Violência de Gênero: Poder e Impotência. Rio de Janeiro: Revinter, 1995.

. Já se Mete a Colher em Briga de Marido e Mulher.

Em: A Violência Disseminada: São Paulo em Perspectiva. Revista da Fundação SEADE, Vol. 13, n 4, pp. 82-91, 2000.

SANTOS, B. S. Pela mão de Alice: o social e o político na pós-modernidade. $13^{\mathrm{a}}$ Ed. São Paulo: Cortez, 2010.

SORJ, B. A nova sociedade brasileira. Rio de Janeiro: Jorge Zahar, 2000.

WEBER, M. Économie et société 2. Paris: Plons, 1995.

Recebido: 21/10/2015.

Aprovado condicionalmente: 05/07/2016.

Aprovação final: 11/08/2016. 